\title{
INVESTIGATIONS ON VERTICAL LAND MOVEMENTS ALONG THE NORTH SEA AND BALTIC SEA COAST IN GERMANY WITH PS INTERFEROMETRY
}

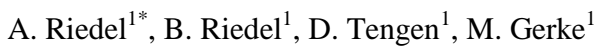 \\ ${ }^{1}$ Technische Universität Braunschweig, Institute of Geodesy and Photogrammetry, Germany - (a.riedel, b.riedel, d.tengen, \\ m.gerke)@tu-bs.de
}

KEY WORDS: Vertical displacement, InSAR, GNSS, Mean Sea level, PS Interferometry

\begin{abstract}
:
The project 'Determinations on the absolute sea-level rise on the German North Sea and Baltic Sea coasts', funded by the Federal Ministry of Education and Research (BMBF), has the overall goal to estimate the absolute sea level change in those coastal areas. A major issue associated with detecting absolute sea level changes is the relative character of tidal records. To calibrate the tidal records, a spatial vertical land movement model for northern Germany has been set up. To this end we combined a network from German Height Reference Systems (Deutsches Haupthöhennetz, DHHN 95 and DHHN 2016), reprocessed data from 180 permanent GNSS stations and results from Persistent Scatterer (PS) Interferometry.

PS processing covers an approximately $50 \mathrm{~km}$ wide strip along the $1200 \mathrm{~km}$ long German coast. We processed two tracks from Sentinel-1A and -1B from October 2014 to September 2018 and generated a combined spatial solution for the estimation of vertical land movement. In general, vertical velocities from PS Interferometry range between $\pm 2 \mathrm{~mm} / \mathrm{a}$ and show a homogeneous distribution for coastal areas. Therefore we consider them as stable. We observe subsidence in the area around Groningen and Emden through hydrocarbon extraction. In Wilhelmshaven and Etzel subsidence associated with cavern storage is visible.

Processed GNSS data and PSI results overlap in time from 2014 to 2016. The integration of the spatial multi-temporal PS results with point-wise GNSS time series data are required, as they form the main input data for the further development of our vertical displacement model of northern Germany.
\end{abstract}

\section{Introduction}

Estimating the absolute sea level change is the goal of the project: 'Determinations on the absolute sea-level rise on the German North Sea and Baltic Sea coasts' funded by the Federal Ministry of Education and Research (BMBF).

A major issue associated with detecting absolute sea level changes is the relative character of tidal records. They include mean sea level changes, tidal signals, the internal movements of the gauge device and movements of the gauge building, as well as vertical movements of the costal surface. To calibrate the tidal records, a spatial vertical land movement model for northern Germany is set up, with extensions of assumptions from Tengen (2010). Those extensions allow us to include linear subsidence and uplift effects as well as non-linear movements from oil and gas extraction.

One part of the database for this model are the repeated measurements from German Mean Height Reference Systems (Deutsches Haupthöhennetz, DHHN 95 and DHHN 2016) and the other parts are a reprocessed network of 180 permanent GNSS stations and results from Persistent Scatterer Interferometry (PSI).

The integration of the spatial multi-temporal Persistent Scatterer (PS) results with point-wise GNSS time series data are necessary as the main input data for the further development of the vertical displacement model for northern Germany. This will finally lead us to a more precise correction term for the tidal records of the gauges and a more accurate estimation of absolute sea level change for the North and Baltic Sea.

\section{Data sets and InSAR processing}

The developed vertical land movement model extends from the German-Danish border in the North to an imaginary line from Leipzig, via Göttingen to Duisburg in the South. The GNSS network includes 180 permanent stations from IGS, EUREF, GREF and SAPOS and stations installed on gauging stations with inhomogeneous RINEX data from January 2010 until end of 2016 (Tengen et al., 2019).

Sentinel-1A and -B data we used for PSI processing, covers an approximately $50 \mathrm{~km}$ wide strip along the $1200 \mathrm{~km}$ long German coast, see figure 1. It also includes Groningen in the north-eastern part of the Netherlands to cover a total area of almost $31.000 \mathrm{~km}^{2}$. The German North Sea coast is represented in descending track 139 and contains 133 acquisitions from October 2014 to March 2018. For the Baltic Sea coast we used ascending track 146 with 130 acquisitions from October 2014 until September 2018. A small connecting strip between Kiel and Wismar with ascending track 117 is still being processed and analysed.

The PSI algorithm developed by Ferretti et al. (2001) was applied to process the data from Sentinel-1 satellites. The tracks were split into patches of around $5.000 \mathrm{~km}^{2}$, due to hard drive limitations, see table 1 . The average overlapping area between individual patches is $500 \mathrm{~km}^{2}$. Processing of the first two patches took several weeks and was done on standard workstation computers. The next six patches were processed on a high-performance computer with two 2 TByte SSD hard drives and took around 6 to 7 days per patch.

To derive vertical displacement velocities we assumed linear displacements for the earth surface changes.

\footnotetext{
* Corresponding author
} 


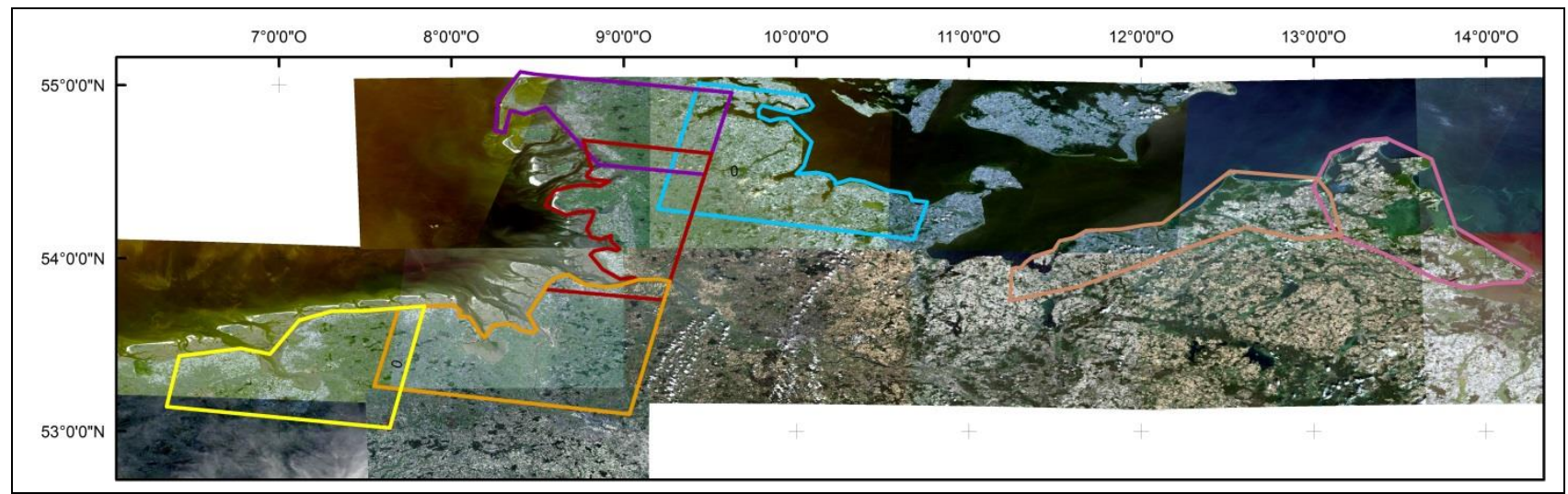

Figure 1: Overview of the area of investigation and the already processed patches (colours related to table 1) from PSI. Background satellite image based on Sentinel-2 data.

\begin{tabular}{|l|l|l|l|l|l|l|}
\hline Name & Extension & $\begin{array}{l}\text { Processed } \\
\left.\text { area } \mathbf{( k m}^{2}\right)\end{array}$ & $\begin{array}{l}\text { Overlapping } \\
\left.\text { area } \mathbf{k m}^{2}\right)\end{array}$ & $\begin{array}{l}\text { Total } \\
\text { number } \\
\text { of PS }\end{array}$ & $\begin{array}{l}\text { Number of PS } \\
\text { in overlapping } \\
\text { area }\end{array}$ & $\begin{array}{l}\text { Velocity difference in } \\
\text { overlapping area } \\
\text { [mm/a] }\end{array}$ \\
\hline Patch1 (P1) & Groningen-Papenburg & 5300 & 510 with P2 & 249890 & 20120 & $-0,1$ \\
\hline Patch2 (P2) & Wilhemshaven-Bremen & 6300 & 450 with P3 & 254713 & $\begin{array}{l}\text { P1: } 25250 \\
\text { P3: } 10401\end{array}$ & $-0,1$ \\
\hline Patch3 (P3) & Cuxhaven-Bredtstedt & 3500 & 580 with P4 & 62580 & $\begin{array}{l}\text { P2: } 13715 \\
\text { P4: } 5500 \\
\text { P5: } 758\end{array}$ & $-0,7$ \\
\hline Patch4 (P4) & & & & & $\begin{array}{l}\text { P3: } 6749 \\
\text { P5: } 13971\end{array}$ & 0,1 \\
\hline Patch5 (P5) & Bredtstedt-Sylt & 3700 & 690 with P5 & 31678 & $\begin{array}{l}\text { P3: } 1202 \\
\text { P4: } 10924\end{array}$ & P3: -0,4 \\
\hline Baltic Sea_West (BS_W) & Wismar-Stralsund & 3500 & 180 with BS_E & 94200 & 12246 & 0,2 \\
\hline Baltic Sea_East (BS_E) & Stralsund- Świnoujście & 3800 & & 72081 & 12117 & \\
\hline
\end{tabular}

Table 1: Overview of size and number resulting PS related to processed patches

Each patch was split into subareas of $200 \mathrm{~km}^{2}$ overlapping each other by $20 \%$, and merged afterwards. Atmospheric corrections were applied by high pass filtering with an annual signal and spatial low pass filtering with a length of $3000 \mathrm{~m}$, coming from experimental processing runs. The final results were projected from line-of-sight to vertical velocities.

\section{Results}

The results from PSI processing, see figure 2, show homogeneous velocities mainly between $\pm 2 \mathrm{~mm} / \mathrm{a}$ over the time period of three and half years and therefore this velocity is considered the signal of stable areas.

We observe uplift and subsidence in the area around Groningen and in Emden. In Wilhelmshaven and Etzel only subsidence is visible. The surroundings of Groningen and Emden show strong subsidence through hydrocarbon extraction. In Wilhelmshaven and Etzel, movements associated with cavern storages are detected (BGR, 2018). North of Winschoten, we observe uplift, which is likely caused by the Blauwestad project: The Oldambtmeer is a nature reserve, which was partly flooded to create a new lake. Positive velocities in the villages close to the Zuuidlardenermeer are of anthropogenic nature and mainly driven by construction activities, like the building of houses and landing places for boats, installation of solar panels on roofs and industrial and agricultural production. In Veendam we observe uplift probably caused by the construction of a new highway intersection and roundabout traffic.
Results are in good agreement with velocities of the Ground motion service of the Netherlands (Nederlands Centrum voor Geodesie en Geo-Informatica (NCG, 2019).

Although those surface motions are not of primary interest for the research questions of the project, they are interesting as they demonstrate the potential of the PS-approach applied to Sentinel-1-data.

The PS results along the Baltic coast are more homogenous than the results for the North Sea coast. Strong subsidence of up to $-4,5 \mathrm{~mm} / \mathrm{a}$ is visible in the old "City Harbour" of Rostock on an area of $10 \mathrm{~km}^{2}$. In 2014 the AIDA high rise bureau was built and has led to subsidence through additional loading on the peat soil (AIDA, 2016; BGR, 1993).

In Ahlbeck uplift driven by sand accumulation processes is visible. On the Isle of Rügen some local coastal erosion effects along the cliff coast are also detectable.

Local effects can mainly be explained by construction activities like installation of solar panels on roofs, solar plants on agricultural fields and re-pavements of roads. Strong road traffic can cause subsidence on very local scale, i.e. on bigger parking lots.

Detailed studies on the overlapping areas were carried out and show very minor offsets of up to $-0,7 \mathrm{~mm} / \mathrm{a}$ between the patches, see table 1. Patch 3 extends from Cuxhaven to Husum and shows an underestimation of velocities in the north in comparison to patches 4 and 5. An offset correction for this patch will be applied based on Kalia et al. (2017). 


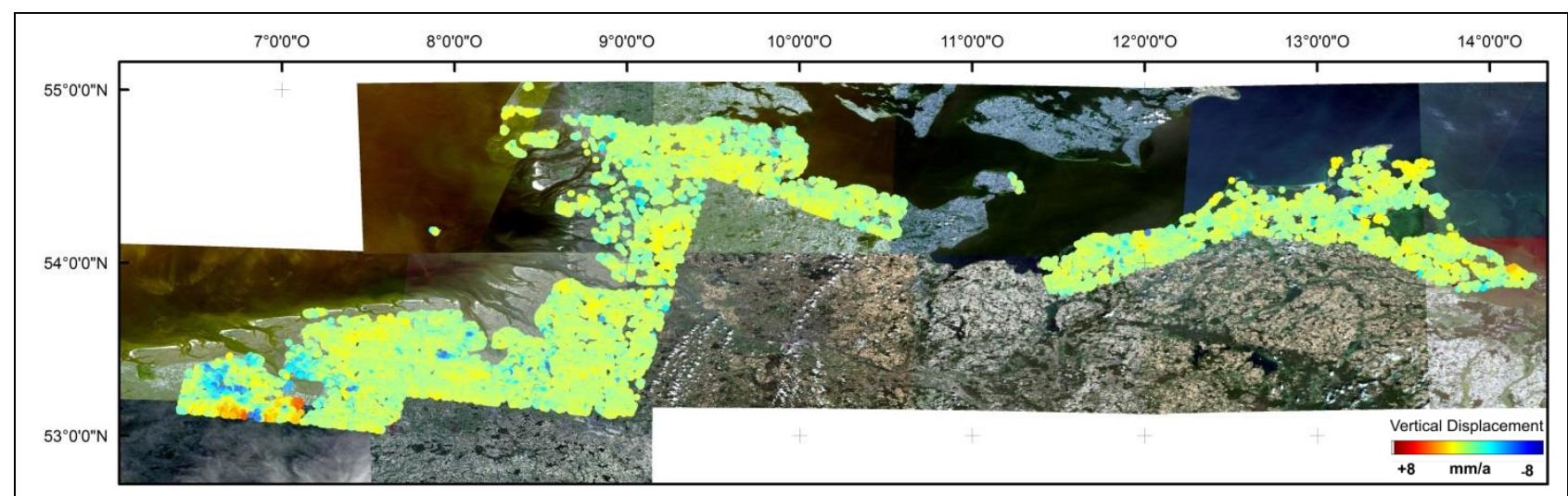

Figure 2: Results from PSI for the North Sea and Baltic Sea coast in Germany and north-eastern part of the Netherlands overlaid on Sentinel-2 data.

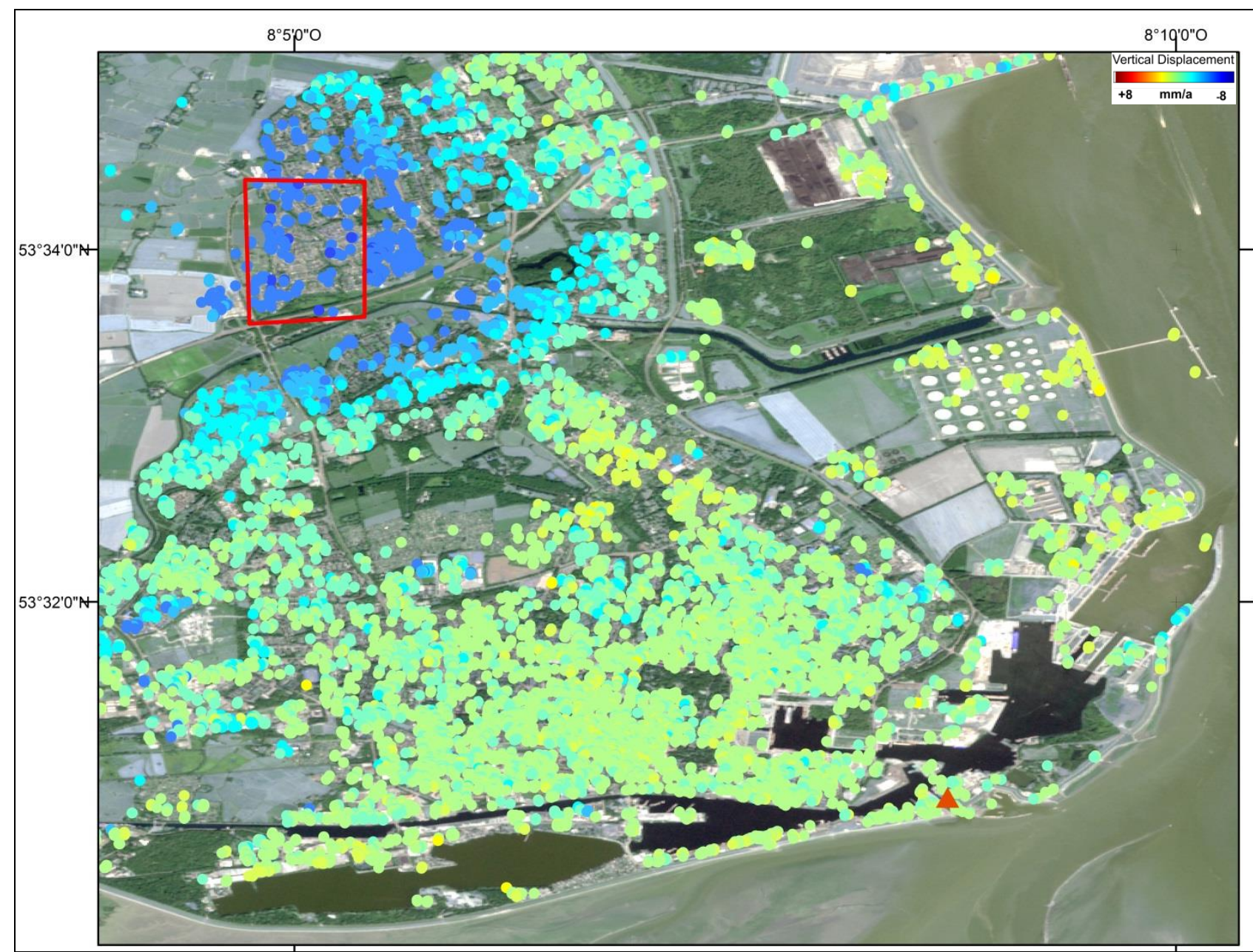

Figure 3: Study area of WH. Red rectangle location of strongest motion, red triangle location of gauging station with installed GNSS

\subsection{Case study Wilhelmshaven}

The city of Wilhelmshaven (WH) is located in the west of the Bay of Jade. The north western part of the city centre shows strong subsidence of up to $-6 \mathrm{~mm} / \mathrm{a}$, see figure 3 red rectangle. The cavern storage Rüstringen triggers these subsiding effects (BGR, 2018). The time series in figure 4 in purple displays the temporal evolution of the time series for a cluster of 426 PS at the strongest moving location. The time series doesn't show strong seasonal effects through atmospheric filtering.
Further investigations on a very local scale focus on results from PSI analysis in comparison to GNSS data. GNSS devices were installed on top of the gauges and have been used to compare the PS results in the vicinity of gauging stations, see figure 3 red triangle. For PS results at the gauging station we implemented the term 'Nearest PS', which is the closest PS Cluster to the gauging station.

The overlapping timespan of these data sets is short for the purpose of comparison and can provide only trend information. 
SAPOS data and InSAR data are overlapping for less than two years.

SAPOS station is located in the southeast of the city, $7 \mathrm{~km}$ away from the fastest moving area. GNSS antennas and receivers are installed on top of the gauging station and was sampling data from 2010 to 2016. The time series, see figure 4 in blue, shows no strong subsiding effect but a high scattering of the relative heights through processing of weekly averages. The standard deviation is $3,3 \mathrm{~mm}$. In a further step, we will produce daily results.

The Nearest PS cluster in WH consists of 6 PS in a distance of $45 \mathrm{~m}$ to the station. The mean velocity is $-1,4 \mathrm{~mm} / \mathrm{a}$. The time series, see figure 4 in red, starts in December 2014 and overlaps GNSS results for two years. The relative height changes show a similar trend to time series from GNSS but with a much lower standard deviation of $1,3 \mathrm{~mm}$. The gauging station is not influenced by the cavern storage

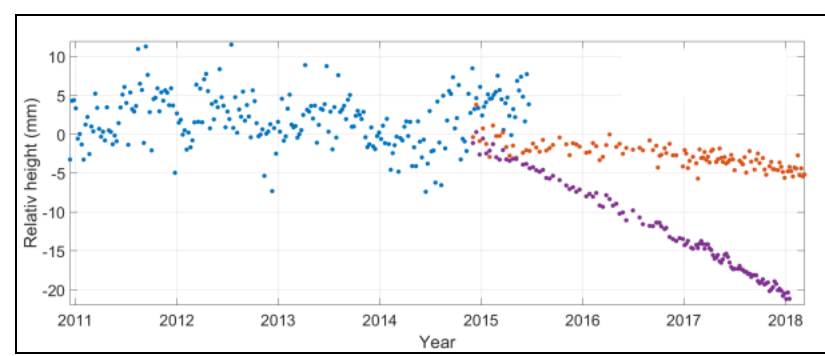

Figure 4: Time series of processed GNSS and PS cluster in WH. In blue are GNSS results at gauging station, in red are results from nearest PS cluster, in purple are PS results of strongest motion area

\subsection{Case study Cuxhaven}

The city of Cuxhaven is located at the mouth of the river Elbe. The gauging station of Cuxhaven Steubenhöft has the longest tidal record for the German North Sea and is therefore of great interest to us for oceanography (Niehüser et al., 2016).

The gauge station is also equipped with a GNSS station, see figure 5 red triangle. The processed GNSS data contains around 355 values of weekly averages and shows a standard deviation of $4,0 \mathrm{~mm}$ for relative heights, see figure 6 . The corresponding InSAR data for the Nearest PS cluster has a lower standard deviation of about $2,2 \mathrm{~mm}$, too. A mean velocity of $0,9 \mathrm{~mm} / \mathrm{a}$ can be calculated from the nearest PS Cluster, which consists of 4 PS in a distance of $200 \mathrm{~m}$ to the gauge station.

GNSS and PS results for the gauging station Cuxhaven Steubenhöft show an incompletely removed seasonal signal, that has to be corrected in a further working step.

\subsection{Case study High Dune}

The district High Dune is north of Rostock at the Baltic Sea. It's located at the mouth of the river Unterwarnow. Processing of patch BS_W shows subsidence in that area, see figure 7. 320 PS were selected in High Dune, which have a mean velocity of $-1,4 \mathrm{~mm} / \mathrm{a}$, see figure 8 with red dots. The nearest PS cluster consists of 2 PS and shows a stronger subsiding trend of $-4,0$ $\mathrm{mm} / \mathrm{a}$, see figure 8 blue dots. The gap between November 2015 and June 2016 is caused by missing Sentinel-1 data acquisitions in that track.

The gauging station and it's gauging bench-mark is influenced by this subsiding motion, so a linkage to the data from the hinterland is in this case study very important to correct tidal records (Riedel et al., 2018).

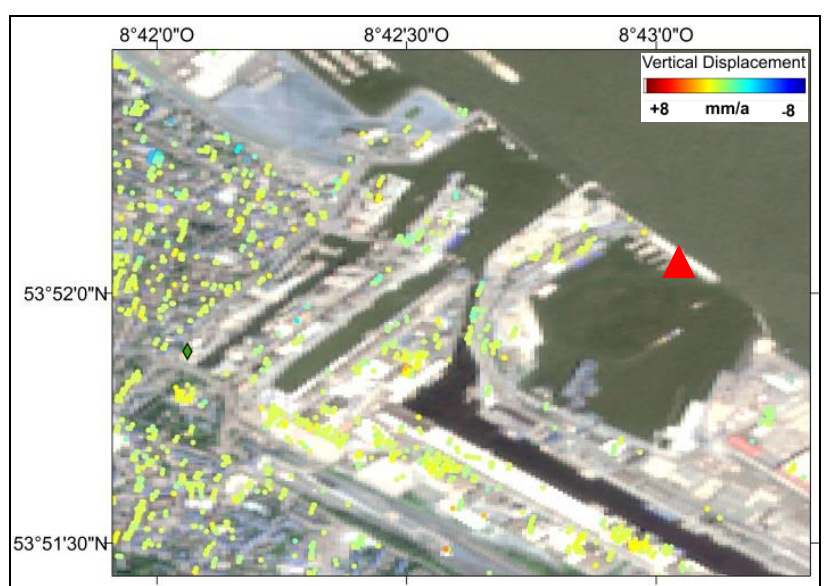

Figure 5: PS results from for Patch 3 at the gauging station Cuxhaven Steubenhöft. Red triangle location of gauging station with equipped GNSS, green diamond location of SAPOS station

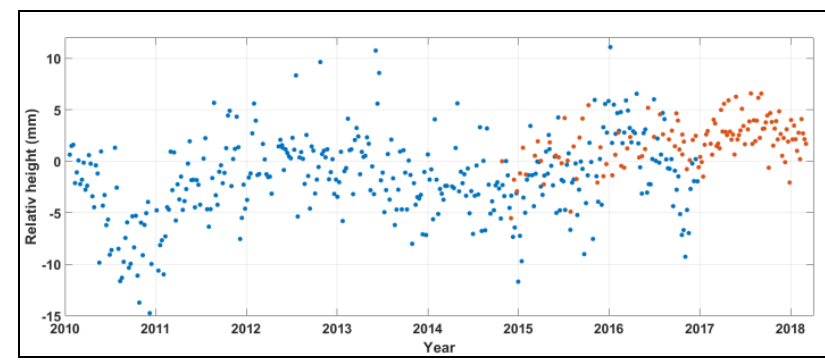

Figure 6: Time series of processed GNSS data and PS cluster at the gauging station of Cuxhaven Steubenhöft

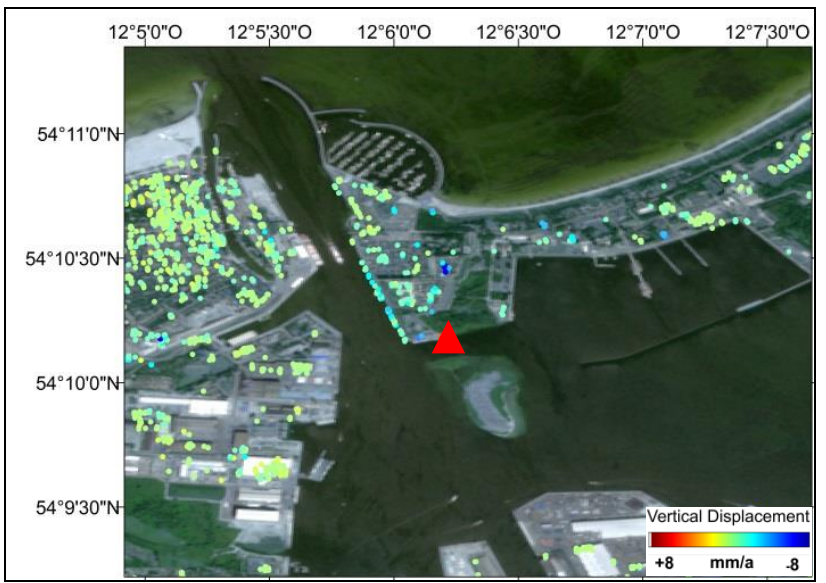

Figure 7: Study area High Dune in Rostock. Red triangle location of gauging station

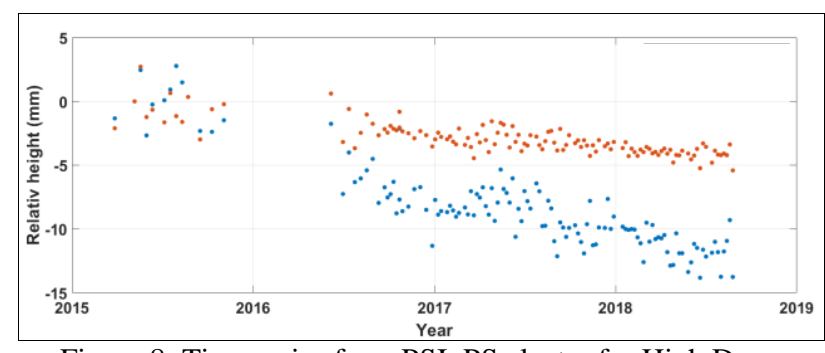

Figure 8: Time series from PSI. PS cluster for High Dune district in red, Nearest PS cluster in blue. The data gap is related to missing Sentinel-1 data. 


\section{Conclusion}

The presented multi-temporal Persistent Scatterer results of Sentinel-1 data from October 2014 to September 2018 form an almost complete spatial velocity map of the coastal areas of the German North- and Baltic Sea coasts.

The presented PS results are in good agreement with velocities of the ground motion service of the Netherlands (NCG, 2019). Displacement rates for Groningen are up to $-8,2 \mathrm{~mm} / \mathrm{a}$ and we calculate slightly slower velocities of up to $-6,6 \mathrm{~mm} / \mathrm{a}$ with a data set of 3.5 years. Uplift effects are located at similar locations but with lower rates of $1,0 \mathrm{~mm} / \mathrm{a}$.

The Deutsches Luft- und Raumfahrtzentrum (DLR, 2018) presents a ground motion map from ERS data from 1991 to 1999 in which strong subsiding effects in Wilhelmshaven are visible as well.

Siefert and Lassen (1985) reported a subsiding trend for the gauging station Cuxhaven Steubenhöft and investigated a correction term for the gauging station. Results from IKÜS (Wanninger et al., 2008) also identify a subsidence trend for the gauge. Weiß and Sudau (2011) mention uplift at the gauge, which would fit our results better.

GNSS and PS data overlap in time just for about two years, but the time series of height changes for Cuxhaven and Wilhelmshaven show good relative agreement in the general trends and absolute values. The standard deviation of GNSS data are still higher than our PS results through the processing of weekly averages. In the next step, we will produce daily averages.

To conclude, presented spatial multi-temporal PS results are validated with external evidence and are used for integration with point-wise GNSS time series data. These are required data sets, as they form the main input data for the further development of our vertical displacement model of northern Germany.

This will finally lead us to a more precise correction term for the tidal records of the gauges and a more accurate estimation of absolute sea level change for the North and Baltic Sea.

\section{ACKNOWLEDGEMENTS}

This research is funded by Federal Ministry of Education and Research (BMBF) with Research Grants 03KIS117.

The Sentinel-1 and -2 data are provided by Open Access

Copernicus, European Space Agency (ESA).

\section{REFERENCES}

AIDA, 2016. https://media.aida.de/fileadmin/user_upload/v4/ Unternehmen/Presse/PM_2016_Q2/AIDA_Kussmund_gr\%C3 $\%$ BC\%C3\%9Ft_Rostock_vom_Dach_des_AIDA_Home.pdf (01.04.2019)

Bundesamt für Geowissenschaften und Rohstoffe (BGR), 1993. Geologic Map of Germany 1:1 000000 (GK1000). BGR, Hannover.

Bundesamt für Geowissenschaften und Rohstoffe (BGR), 2018. Map of Mining and Storage Operations of the Federal Republic of Germany 1:2 000000 (BergSP). BGR, Hannover.

Deutsches Luft- und Raumfahrtzentrum (DLR), 2018. https://www.dlr.de/eoc/Portaldata/60/Resources/images/3_imf_ sv/DefoDE_BIG_2048.jpg. (30.03.2019).
Ferretti A., Prati C., and Rocca F., 2001. Permanent scatterers in SAR interferometry. In: Geoscience and Remote Sensing, IEEE Transactions, Vol. 39 (1), pp. 8 - 2.

Kalia, A.C., Frei M., and Lege T., 2017. A Copernicus downstream-service for the nationwide monitoring of surface displacements in Germany. In: Remote Sensing of Environment, Vol 202, pp. 234-249.

Nederlands Centrum voor Geodesie en Geo-Informatica (NCG) 2019. https://bodemdalingskaart.nl (26.03.2019)

Copyright ( ) NCG 2019.

Niehüser, S., Jensen, J., Wahl, T., Dangendorf, S., and Hofstede, J. 2016. Zum Einfluss möglicher Setzungserscheinungen am Leuchtturm Cuxhaven auf die langjährigen Wasserstandsaufzeichnungen am Pegel Cuxhaven Steubenhöft. In: Die Küste, Vol 84, pp. 119-145, https://hdl.handle.net/20.500.11970/105215.

Riedel, B., Kracke J.-N., Tengen D., Riedel A., Gerke M. and Niemeier W. 2018. Bestimmung vertikaler Landbewegungen an der deutschen Nordseeküste. Tagungsband GeoMonitoring 2018, pp. 167-180.

Siefert, W. and Lassen, H. 1985. Gesamtdarstellung der Wasserstandsverhältnisse im Küstenvorfeld der Deutschen Bucht nach neuen Pegelaufzeichnungen. In: Die Küste, Vol. 42, pp. 1-77, https://hdl.handle.net/20.500.11970/101217.

Tengen, D., 2010. Höhenveränderungen im Bereich der niedersächsischen Nordseeküste bestimmt aus Nivellement- und GPS-Messungen. Dissertation TU Braunschweig, ISBN 3926146-21-4.

Tengen, D., Riedel, A., Riedel, B., Gerke, M. and Niemeier, W. 2019. Ableitung vertikaler Landbewegungen an der deutschen Nord- und Ostseeküste aus GNSS- und PS-Auswertungen. In: Tagungsband GeoMonitoring 2019, pp. 121-133, https://doi.org/10.15488/4517.

Wanninger, L., Niemeier, W., Jahn, C.H. and Sudau, A. 2008. Aufbau eines integrierten Höhenüberwachungssystems in Küstenregionen durch Kombination höhenrelevanter Sensorik (IKÜS). Abschlussbericht KFKI Projekt 03KIS055-058, Dresden, https://hdl.handle.net/20.500.11970/101641.

Weiss, R. and Sudau, A. 2011. Satellitengestützte Überwachung der Pegelnullpunktehöhe in der Deutschen Bucht. In: Die Küste, Vol 78, pp. 1-32,

https://hdl.handle.net/20.500.11970/101658. 